\title{
A corporeidade tênue e intensa no cotidiano escolar
}

Andreza Oliveira Berti

Mestre em Educação pela UNIMEP

\section{Resumo}

Este artigo pretende dialogar com as experiências de aprendizagens em diferentes cotidianos escolares da rede municipal de ensino do Rio de Janeiro. Com a perspectiva de potencializar a corporeidade, me aproximo de Deleuze e Guattari ao não definirem o corpo como somatório de partes e sim, como composições de afectos, problematizando os conceitos dualistas que separam o eu e o mundo, o eu e os outros, o eu e o corpo. Manifesto, portanto, o desejo por uma filosofia que assuma o conhecimento como inscrição corporal. Enfim, incluo-me na caminhada ética e estética em favor da corporeidade contextualizada e múltipla.

Palavras-chave: Corporeidade; Cotidianos Escolares; Aprendizagens.

\begin{abstract}
This article intends to dialogue with different learning experiences in school everyday from public schools in the city of Rio de Janeiro. With the prospect of enhancing the corporeity, I approach Deleuze and Guattari when do not define the body as the sum of parts but, as compositions of affection, questioning the dualistic concepts that separate self and world, self and others, self and body. Manifest, therefore, the desire for a philosophy that assumes knowledge as inscription body. Finally, include myself in the walked ethics and esthetics in favor of corporeity contextualized and multiple
\end{abstract}

Key-words: Corporeity; Everyday School; Learning. 


\section{Corpo tênue}

I

nicio este artigo acolhendo as considerações feitas por Assmanm (1995), na obra Paradigmas educacionais e corporeidade, acerca

da relevância do estudo da corporeidade e de sua inter-relação com a educação. Então, por que estudar a corporeidade? Porque a considero como ponto de conexão para se problematizar os conceitos dualistas que insistem em 'ditar as regras' no cenário educacional, separando o eu e o mundo, o eu e os outros, o eu e o corpo.

E, a partir disso, com o intuito de potencializar a corporeidade no cotidiano dos anos iniciais do Ensino Fundamental, desenvolvo minha argumentação apoiada em Deleuze e Guattari (1997, p. 47) ao não definirem o corpo pelo que o compõe: "um corpo não se define pela forma que o determina, nem como uma substância ou sujeitos determinados, nem pelos órgãos que possui ou pelas funções que exerce”. Parto da premissa de que o corpo é muito além de um somatório de fragmentos; na tentativa de não mais vê-lo como um objeto de manipulação científica, ou mesmo educativa, a qual determinava (ou ainda determina?) o corpo apenas como residência da mente.

Neste movimento de não mais compreender o homem similar a uma máquina, para além de uma "tese dual”, o pensamento sistêmico nasce como uma teoria que pretende entender os sistemas vivos como integrados - o que permite avançar no entendimento do corpo não como somatório de fragmentos.

Sendo assim, o pensamento sistêmico envolve uma mudança da ciência objetiva para a ciência epistêmica, em direção a um esboço no qual a epistemologia (o método do questionamento) torna-se parte integral das teorias científicas. Ou seja, uma teoria que contextualiza e explica o homem incluído em um universo maior. Imerso em redes de relações complexas, fluidas. 
Em linhas muito gerais, refere-se a um todo organizado cujos componentes se encontram em interação dinâmica. É fundamental que se capte este elemento novo: a dinâmica nãolinear das interações que constitui o tipo de sistemas dos quais se ocupam preferencialmente as teorias sistêmicas. (Assmann, 1998, p. 180).

A abordagem sistêmica desloca o foco da função para a organização. A noção de sistema engendra progressivamente os conceitos de autorregulação, de processo e de rede.

Neste processo investigativo em torno de pensamentos e/ou teorias que ajudem a compreender a “constituição” filosófica, científica e educativa da corporeidade, deparo-me com o termo auto-organização para explicar a dinâmica dos seres vivos.

De acordo com as pesquisas desenvolvidas por Maturana (2001) na área biológica, o sistema nervoso funciona como uma grande rede de interações e à medida que se organiza em "relações interativas" sofre alterações em seus elementos e, consequentemente, resulta (rá) alterações em outros ou nos mesmos componentes. Logo, a produção e a transformação dos componentes são mantidas de forma circular, bem como a organização da vida. Diante desta condição, o biólogo radicalizou ao afirmar que esta organização circular da vida é a mesma encontrada no processo de cognição.

Para Maturana (2001), o termo "autopoiese" traduz o que ele chamou de centro da dinâmica constitutiva dos seres vivos. Para exercê-la de modo autônomo, eles precisam recorrer a recursos do meio ambiente. Em outros termos, são ao mesmo tempo autônomos e dependentes. Trata-se, pois, de um paradoxo. Essa condição paradoxal não pode ser bem entendida pelo pensamento linear, para o qual tudo se reduz a binariedade do sim/não, do ou/ou. Diante de seres vivos, coisas ou eventos; o raciocínio linear analisa as partes separadas, sem empenhar-se na busca das relações dinâmicas entre elas.

A identificação de que sistemas vivos são sistemas cognitivos, permitiu o encontro de Maturana com Varella (neurocientista), para juntos 
trabalharem na descrição detalhada da nova concepção: autopoiese $^{1}$, a “autocriação". Assim sendo, eles constataram que a autopoiese "é um padrão geral de organização comum a todos os sistemas vivos, qualquer que seja a natureza dos seus componentes” (Capra, 1996, p. 89). Estes componentes são continuamente produzidos e produtores de toda a rede e, portanto, de si mesmos.

O corpo biológico, para Maturana e Varella (1995), não se constitui exclusivamente de aparelhos, de sistemas, de músculos, de ossos e de pele, mas sim de uma unidade formada por aspectos biológicos, psicológicos, físicos, sociais e culturais. Os seres vivos recriam-se constantemente e aprendem em relação interativa com o meio. Os sistemas vivos são sistemas cognitivos e a vida é um processo de cognição.

Dito isso, os autores sugerem que se deve superar a concepção fragmentada e mecanicista dos sistemas vivos, dando lugar à visão sistêmica cujos processos auto-organizativos interagem e cooperam.

Nesta busca incessante pela superação da dicotomia corpo/mente cérebro/mente (ou qualquer outra divisão impulsionadora de inúmeras mazelas decorrentes da fragmentação do ser humano), Maturana e Varela desenvolveram uma teoria sistêmica da cognição, conhecida como teoria de Santiago. De acordo com esta teoria,

o cérebro não é necessário para que a mente exista... Os organismos mais simples são capazes de percepção, e portanto de cognição. Eles não vêem, mas, não obstante, percebem mudanças em seu meio ambiente... A nova concepção de cognição, o processo do conhecer, é, pois muito mais ampla do que a concepção do pensar. Ela envolve percepção, emoção e ação - todo o processo da vida. (Capra, 1996, p. 145).

Estes estudos são imprescindíveis à construção de uma filosofia, ciência e educação que se desejam potentes, pois através deles podemos compreender o processo da vida e o processo do conhecer como dimensões

\footnotetext{
${ }^{1}$ Assmann (1998, p. 136) esclarece ainda mais o termo quando afirma: "os processos autopoiéticos devem ser imaginados como multiplicidade de níveis interligados e emaranhados".
} 
inseparáveis do ser humano. E com isso, impulsionar o questionamento das visões que se dizem "melhores” ou “únicas”.

Ao romper com o modelo cartesiano, não mais fazendo distinção entre corpo e mente, razão e emoção e tantas outras polaridades, autores como Assmann, Maturana, Varela e Capra têm buscado trabalhar dentro de uma perspectiva da totalidade corporal e, a meu ver, impulsionando a construção da noção de corporeidade.

\section{Corpo Intenso}

Fazendo ponte com as abordagens complexas e epistêmicas, recupero as análises filosóficas de Deleuze e Guattari (1996) sobre a discussão iniciada pelo poeta, ator e diretor de teatro Antonin Artaud: a "declaração de guerra aos órgãos”. A luta contra a formação e constituição dos órgãos, isto é, do organismo.

A ideia de Corpo sem órgãos (CsO) ${ }^{2}$ de Artaud (1988), declamada no poema O homem-Árvore, retrata o avesso do “organismo”. O organismo é uma leitura que se pode fazer do corpo e deriva da ideia de que, por dentro, obedecemos a uma organização sistemática, a qual nos explica e nos determina. Eis um trecho da poesia:

o tempo em que o homem era uma árvore sem órgãos nem função, mas de vontade e árvore de vontade que anda, voltará. Existiu, e voltará. Porque a grande mentira foi fazer do homem um organismo, ingestão, assimilação, incubação, excreção, o que existia criou toda uma ordem de funções latentes e que escapam ao domínio da vontade decisora, a vontade que em cada instante decide de si; porque assim era a árvore humana que anda, uma vontade que decide a cada instante de si, sem funções ocultas, subjacentes, que o inconsciente rege. Do que somos e queremos na verdade pouco resta, um pó ínfimo sobrenada, e o resto, Pierre Loeb, o que é? Um organismo de engolir, pesado na sua carne, e que defeca e em cujo campo, como um irisado distante, um arco-íris de reconciliação com

\footnotetext{
2 “(...) Não é uma noção, um conceito, mas antes uma prática, um conjunto de práticas. Ao Corpo sem Órgãos não se chega, não se pode chegar, nunca se acaba de chegar a ele, é um limite. Diz-se: que é isto - CsO - mas já se está sobre ele...” (Deleuze e Guattari, 1996, p. 9)
} 
deus, sobrenadam, nadam os átomos perdidos, as ideias, acidentes e acasos no total de um corpo inteiro... (Artaud, 1988, p. 105).

Segundo Artaud (1988) neste poema, os órgãos nos foram extraídos, estudados, classificados e registrados minuciosamente, ou seja, (re) conhecidos como órgãos a que correspondem funções. Assim, passamos a ter uma inscrição em nós que permite o discurso "sobre o corpo" - uma representação que nos representa, que nos aprisiona. Ora, dizem Deleuze e Guattari (1996, p.21): “o corpo é o corpo (...) O corpo sem órgãos grita: fizeram-me um organismo! Dobraram-me indevidamente! Roubaram meu corpo!”.

Neste processo de descoberta do corpo, de um caminhar rumo a corporeidade, Deleuze e Guattari (1996, p. 22) contribuem ao dizer: "Desfazer o organismo nunca foi matar-me, mas abrir o corpo a conexões que supõem todo um agenciamento, circuitos, conjunções, superposições e limiares, passagens...”. Em suma, é uma forte vontade de ser pleno, de ser

(...) necessariamente um lugar, necessariamente um plano, necessariamente um coletivo (agenciando elementos, coisas, vegetais, animais, utensílios, homens, potências, fragmentos de tudo isto, porque não existe 'meu' corpo sem órgãos, mas 'eu' sobre ele, o que resta de mim, inalterável e cambiante de forma, transpondo limiares). (Deleuze e Guattari, 1996, p. 24).

Ao retorquir a leitura reducionista, a partir da qual a "grande mentira foi fazer do homem um organismo, ingestão, assimilação, incubação, excreção...” (Artaud, 1988, p.105), assumo um compromisso com a corporeidade na expressão dos sentidos, nas imagens refletidas, nos silêncios falantes, nos vestígios exibidos, na expressão do corpo incorporado... Em um vai-e-vem constante de possibilidades reinventadas e (re) descobertas.

Deleuze e Guattari (1997, p. 42) na busca pela compreensão da potência do agir dos sujeitos afirmam: “assim como evitávamos definir um corpo por seus órgãos e suas funções, evitamos defini-lo por características Espécie ou Gênero: procuramos enumerar afectos”. E, movidos pelo 
questionamento espinosista “o que pode um corpo?”, os autores são enfáticos ao dizer:

Não sabemos nada de um corpo enquanto não sabemos o que pode ele, isto é, quais são seu afectos, como eles podem ou não compor-se com outros afectos, com os afectos de um outro corpo, seja para destruí-lo ou ser destruído por ele, seja para trocar com esse outro corpo ações e paixões, seja para compor com ele um corpo mais potente (Deleuze e Guattari, 1997, p. 43).

Desse modo, Deleuze e Guattari, afirmam ser possível ultrapassar a questão das dualidades, classificações e organizações existentes na compreensão do mundo. Basta incluir nas observações cotidianas a noção de multiplicidade, pois através do conceito multiplicidade, é possível desmedir o esquema binário uno-múltiplo.

Voltemos a esta história de multiplicidade, porque foi um momento muito importante quando foi criado tal substantivo, precisamente para escapar da oposição abstrata entre o múltiplo e o uno, para escapar da dialética, para chegar a pensar o múltiplo em estado puro, para deixar de fazer dele o fragmento numérico de uma Unidade ou Totalidade perdidas ou, ao contrário, o elemento orgânico de uma unidade ou totalidade por vir - e, sobretudo, para distinguir tipos de multiplicidade. (Deleuze e Guattari, 1995, p. 46).

Neste sentido, podemos perceber que não somos mais um ou dois, mas tantos (vários) que se articulam, se interpretam, se relacionam, se afectam $^{3}$.

Através das pistas apontadas pelas teorias acerca da cognição, do conhecimento, do $\mathrm{CsO}$, da auto-organização, da multiplicidade diferentemente das justificativas mecanicistas - teço fios de possibilidades à construção da corporeidade na escola.

Portanto, na perspectiva de não negligenciar o sujeito, sugiro pensar a corporeidade como processo não linear e não estático; como corpo manifestado e múltiplo; como devir (vir-a-ser, sendo!). Refletir. Mas, não

\footnotetext{
${ }^{3}$ No entender de Deleuze e Guattari (1997, p. 21), “o afecto não é um sentimento pessoal, tampouco uma característica, ele é a efetuação de uma potência de matilha, que subleva e faz vacilar o eu”.
} 
somente isto. Viver e manifestar com toda a intensidade a corporeidade, assumindo e estabelecendo possíveis agenciamentos com o que somos, temos, consagramos ou nem mencionamos.

\section{A corporeidade na escola}

Há diversos debates na contemporaneidade sobre como os diferentes espaços sociais entendem a noção de corpo, sujeito e subjetividade. Entre eles, a escola. Logo, potencializar o corpo no cotidiano escolar expõe um grande desafio. Neste desafio, ao considerá-lo histórico, entrelaço-o com diferentes tempos, espaços, conjunturas econômicas, grupos sociais, étnicos etc. Enfim, existe um corpo provisório e mutante, suscetível a fazer parte das tessituras de conhecimentos: um corpo que transita por vários ambientes. Isto é, "lugar da Biologia, das expressões psicológicas, dos receios e fantasmas culturais, o corpo é uma palavra polissêmica, uma realidade multifacetada” (Sant'Anna, 1995, p. 12).

Ao se criar contatos de um corpo junto ao outro, assumindo-se não como mero portador de agentes culturais - eu tenho um corpo - mas como produtor de movimentos histórico-político-econômico-sociais - eu sou corpo - localizado num determinado tempo e espaço, proponho práticas mais audaciosas, sensíveis e emancipatórias.

Analisando o ensino contemporâneo, em muitas práticas e discursos, existe uma busca incessante para dar sentidos às disciplinas, em se realizar interconexões que expressem uma percepção globalizante da realidade, em tornar o processo de ensino-aprendizagem mais prazeroso. Para endossar este argumento cito Gallo (2003, p. 86) que, ao pensar para além do pedagógico, coloca o problema das disciplinas escolares como um problema epistemológico:

precisamos compreender os processos históricos e sociais de produção de saberes, para podermos compreender as possibilidades de organização e produção desses saberes na escola, ou mesmo no contexto educacional mais amplo. 
Neste esforço em superar uma visão fragmentada, surgem propostas interdisciplinares, multidisciplinares, pluridisciplinares, transdisciplinares, isto é, pensar as disciplinas do currículo de forma integradas e interrelacionadas. Morin (2000, p. 78), em seu artigo Articular os Saberes, sintetiza estes paradigmas ao dizer: "a interdisciplinaridade pode significar, pura e simplesmente, que diferentes disciplinas se reúnam”, ou pode significar “troca e cooperação” (idem). Tanto a multidisciplinaridade quanto a pluridisciplinaridade podem estabelecer a "associação de disciplinas ao redor de um projeto ou de um objeto que lhes é comum” (idem). E, a transdisciplinaridade, que “caracteriza-se muitas vezes por esquemas cognitivos que atravessam as disciplinas, às vezes com tal virulência que as colocam em sobressalto” (ibidem, p.79).

Estas propostas correspondem a uma diferente etapa do desenvolvimento do conhecimento, vindo atuar como mediadoras entre as diferentes disciplinas, enquanto elemento teórico-metodológico da diferença e da criatividade. Estas propostas inter/multi/pluri/trans atuam diretamente nos projetos pedagógicos da escola, sendo ações intencionais, com um sentido explícito; estando intimamente articuladas às questões de ensinoaprendizagem, currículo, corpo docente e discente etc.

Cada vez mais, brota a urgência de uma educação escolar que construa e produza conhecimentos para o transbordamento da vida. Não cabe mais um sistema disciplinar compartimentalizado em áreas do conhecimento. Pois, a redução e a simplificação das disciplinas escolares secundariza as ações, as interações e os acontecimentos presentes no cotidiano das aulas, inibindo a aprendizagem. Uma vez que,

o aprender não se resume em aprender coisas, se isto fosse entendido como ir acrescentando umas coisas aprendidas a outra, numa espécie de processo acumulativo semelhante a juntar coisas num montão. A aprendizagem não é um amontoado sucessivo de coisas que se vão reunindo. Ao contrário, trata-se de uma rede ou teia de interações neuronais extremamente complexas e dinâmicas, que vão criando estados gerais qualitativamente novos no cérebro humano. (Assmann, 1998, p. 40). 
À medida que compreendo a corporeidade como uma opção teórica potente agregada e agregadora de outras teorias como a teoria da autoorganização (autopoiése), a teoria do $\operatorname{caos}^{4}$, a teoria sistêmica ${ }^{5}$, por exemplo, busco assumir e viver uma teoria da corporeidade que se entende como múltipla/multidimensional/relacional.

Ao aproximar estas recomendações teóricas das ideias propostas nos Parâmetros Curriculares Nacionais (PCNs) do primeiro e segundo ciclos do Ensino Fundamental, é possível perceber indicadores sobre o atual sistema educacional brasileiro.

Os PCNs apontam como princípio didático geral à formação de alunos autônomos, críticos e participativos, adotando um eixo teóricometodológico em prol da diversidade, da cooperação e da igualdade. Visto que, corresponde

a necessidade de referenciais a partir dos quais o sistema educacional do País se organize, a fim de garantir que, respeitadas as diversidades culturais, regionais, étnicas, religiosas e políticas que atravessam uma sociedade múltipla, estratificada e complexa, a educação possa atuar, decisivamente, no processo de construção da cidadania, tendo como meta o ideal de uma crescente igualdade de direitos aos cidadãos, baseado nos princípios democráticos. (Brasil, 1997, p. 13).

Neste processo, evitando a fragmentação e o isolamento das disciplinas no interior das escolas, por meio de proposições de políticas públicas, os PCNs definem referenciais curriculares de qualidade para a educação no Ensino Fundamental e Ensino Médio em todo o Brasil. O documento de introdução aos PCNs sustenta a necessidade dessa referência comum para todo o país, porque aposta no fortalecimento da unidade nacional. "Não configuram, portanto, um modelo curricular homogêneo e impositivo” (Brasil, 1997, p. 13). Assim,

\footnotetext{
${ }^{4}$ Entendida como um fenômeno matemático, físico, biológico e sócio histórico que atribui aos sistemas complexos, organizações caóticas e criativas.

${ }^{5}$ Mudança radical das partes para o todo, em uma grande teia de relações.
} 
a orientação proposta nos PCNs reconhece a importância da participação construtiva do aluno e, ao mesmo tempo, da intervenção do professor para a aprendizagem de conteúdos específicos que favoreçam o desenvolvimento das capacidades necessárias à formação do indivíduo. Ao contrário de uma concepção de ensino e aprendizagem como um processo que se desenvolve por etapas, em que a cada uma delas o conhecimento é acabado, o que se propõe é uma visão de complexidade e da provisoriedade do conhecimento (Brasil, 1997, p. 44).

O mesmo encaminhamento é dado à proposta curricular do município do Rio de Janeiro (MultiEducação, 1996), que foi construída na tentativa de garantir o acesso de professores e alunos às informações, contribuindo para o trabalho pedagógico das Unidades Escolares.

Examinando estes documentos, a fim de identificar pistas sobre como se pensa a corporeidade no cotidiano das escolas (mesmo que este cotidiano, em um primeiro momento, seja o da Educação Física), deparei-me com a recomendação de se (re) pensar o conceito de corpo a partir das histórias de vida dos sujeitos aprendentes, ressignificando e integrando as discussões de cultura, de tempo e de espaço.

De acordo com as orientações dos documentos, as aulas de Educação Física se apoiam na concepção de cultura corporal e na compreensão do corpo de forma integrada e não como "partes” aleatórias. Ou seja, como corpo vivo, interativo.

O documento curricular do Rio de Janeiro, igualmente aos PCNs, ainda não inclui em seu texto a palavra corporeidade, mas aponta algumas ressignificações do entendimento do corpo. Porém, ao centralizar a discussão do corpo nas atividades de Educação Física, delega ao profissional desta área a exclusividade das questões corporais.

Não obstante, ao finalizar a abordagem das questões corporais no texto da Educação Física, a MultiEducação (1996, p. 178) propõe “possíveis articulações com as demais áreas do conhecimento e com as mais variadas situações escolares”. Estes indícios de articulação com as áreas do 
conhecimento nos servem para legitimar uma abordagem pedagógica em torno da corporeidade por todos os professores no interior das escolas.

A MultiEducação entende que os saberes e os fazeres organizados nos cotidianos escolares são instituídos sócio historicamente, de acordo com a práxis pedagógica de cada comunidade. Enfim, este documento pressupõe a seleção e a organização dos conhecimentos específicos a práticas formais, institucionais e intencionais do processo de ensino e de aprendizagem das crianças.

Ao dialogar com a MultiEducação - mesmo que de forma breve procuro contextualizar os cotidianos escolares dos quais falo, introduzindo minhas reflexões, interlocuções e experiências perpassadas pelos indicativos da Secretaria Municipal de Educação do Rio de Janeiro, articuladas aos Projeto Políticos Pedagógicos (PPPs) das Unidades Escolares.

Portanto, para este artigo, dialogo com algumas experiências educativas, entendendo-as como potencializadoras das corporeidades dos/as estudantes.

Sendo assim, a oficina "aluno-escritor”, realizada com três turmas de Unidades Escolares da periferia da cidade do Rio de Janeiro (alfabetização, isto é, $1^{\circ}$ ano de escolarização, Classe de Progressão e $3^{\circ}$ ano de escolarização), surgiu como desafio para os grupos. Embora as turmas fossem diferentes, ambas estavam em processos escolares parecidos: a alfabetização ou a “consolidação” da mesma.

Neste movimento, as histórias orais serviram como ponto de partida para despertar a fala/leitura/escrita dos/as alunos/as, ao passo que permitia a introdução de temas, palavras e fonemas. Ou, no dizer de Freire (1988), como temas geradores a fim de impulsionar a aprendizagem.

Era impressionante como os alunos gostavam de ouvir as histórias, recontá-las e criarem em cima delas, a partir de suas próprias. E neste ir-evir de formas, estruturas, ritmos, significados, significantes, ideias e sentimentos, pouco a pouco se revisitavam os temas surgidos. 
No desenrolar das histórias os alunos apropriavam-se da linguagem e entravam em contato com diversas tipologias textuais (literárias, jornalísticas, histórias em quadrinhos, correspondências, textos não verbais etc), sentindo-se à vontade para expressar seus sentimentos, impressões e valores; ao mesmo tempo em que elaboravam e criavam suas próprias fantasias. Deste modo, os alunos familiarizavam-se com o registro escrito das ideias e aumentavam o número de leituras, pois percebiam que a leitura dos livros aprimorava a escrita e aguçava ainda mais a imaginação. Neste percurso, as atividades ficaram cada vez mais estimulantes e preciosas e, claro, não gostaria de perder estas produções. Então, como compilar este material?

Para isto, busquei apoio no Projeto Abrace um Aluno Escritor ${ }^{6}$ para saber quais encaminhamentos seriam necessários para a turma publicar um livro e “embarcar na aventura”.

E assim, seguimos nas produções gradativas de textos diversos (de forma coletiva e individual), traçando ideias e perfis, compondo capítulos, ilustrando fragmentos, descrevendo lugares e personagens, elegendo eixos de análises até chegar ao tema desenvolvido pela turma.

A cada "capítulo" escrito revisava-se o texto e o destino das personagens. Ao fim da correção, abria-se o debate para o grupo, com a intenção de dar continuidade às outras partes do livro, ou voltar ao início.

Com a finalização da “obra” houve a culminância do projeto, em um grande evento na comunidade. Foram espalhados pela escola e entorno (mercados, padarias, farmácias, papelarias etc.) convites e cartazes. Neste acontecimento os “alunos-escritores” explicaram o processo de produção do texto, autografaram os livros e receberam certificados como reconhecimento do trabalho.

\footnotetext{
${ }^{6}$ É um projeto social e pedagógico, criado por um grupo de professores do ensino público do Rio de Janeiro com o intuito de aproximar o jovem e a criança do livro. Não só como leitor, mas, principalmente, como produtor dos seus próprios textos, através de oficinas de produção textual, ilustração e editoração.
} 
Ao editar e produzir livros com os alunos foi possível ampliar e, ao mesmo tempo, ressignificar a identidade local. Não gostaria que as produções escritas e orais dos educandos/as realizadas no cotidiano escolar fossem perdidas e invisibilizadas. No momento do lançamento do livro, foi apresentado aos familiares, amigos e toda a escola o potencial de cada um. Os/as alunos/as afirmaram suas identidades, sentindo-se potentes. Enfim, toda a comunidade escolar se mobilizou e apoiou o evento e, consequentemente, a concretização desse sonho.

Ainda na linha das oficinas, em outra escola, desta vez não mais como responsável por um grupo, mas como professora de sala de leitura transitando por várias turmas - a experiência com a leitura e escrita se configurou de maneira diferente. Inicialmente, a mim cabia o "papel” de mobilizar a escola para a importância da leitura. Entretanto, como desempenhar esta função? De que aspecto literário falaria?

Pois bem, diante de tantas possibilidades, o enunciado multicultural grafite atravessou os tempos e os espaços e permitiu experimentar a força da corporeidade ao reconhecer a potência dos/as alunos/as.

Neste processo de experimentação, vivemos o projeto Grafitagem: (re)descobrindo e (re)construindo as identidades dos alunos/as, no qual todos os integrantes se reconheceram a partir de suas diferentes manifestações identitárias. Esta atividade contou com a colaboração dos estudantes do segundo segmento (ensino regular e educação de jovens e adultos) que frequentavam a sala de leitura. Com a finalidade de conhecer um pouco mais do assunto, um grupo de alunos-colaboradores iniciou a pesquisa e a reflexão acerca do tema.

As atividades iniciais do projeto focaram a percepção da identidade. Partindo da identidade primeira que todos temos/somos: O nome. A partir dos debates e dinâmicas realizadas com indagações simples (Por que temos este nome? Quem o sugeriu? Qual a história deste nome em nossas famílias? Gosto do meu nome? Por quê? Se não gosto, que nome gostaria de ter? Por quê?...), construímos nossa identidade nominal com técnicas 
artísticas primárias, anteriores a grafitagem, que evidenciaram uma leveza no encontro com a diversidade e particularidade dos nomes. Com isso, ampliamos as noções de diferente, único e múltiplo encontradas nos nomes.

Ao longo dos encontros caracterizamos o grafite como expressão urbana, reveladora de diferentes realidades. Os elementos disparadores dos debates foram os conhecimentos prévios dos próprios alunos acerca das suas identidades e desta prática multicultural. Procuramos destacar as contradições experimentadas na escola, pretendendo minimizar - e até erradicar - a divisória que se coloca entre os saberes produzidos ‘dentro’ e 'fora' da escola. E, com a contribuição de Veiga-Neto (2003, p. 113), revelamos o cuidado que a escola deve ter em:

não imaginar que a escola esteja aí para necessariamente dar respostas para o mundo. Não existe um mundo lá e uma escola aqui que dê respostas a esse mundo que parece estar lá. Existe, certamente, uma instituição chamada 'escola' que está implicada neste mundo no sentido mais profundo, no sentido mais íntimo, no sentido até de estabelecer o que é este mundo. A rigor, não existe essa dicotomia de uma instituição dando resposta ao mundo.

No processo metodológico do projeto Grafitagem: (re)descobrindo e (re)construindo as identidades dos alunos/as, iniciamos estudos sobre o grafite. O que é? Aonde surgiu? Quais foram os desdobramentos no Brasil? Como ocorreu a mudança da pichação para a técnica artística da grafitagem no fim da década de 70 até sua manifestação na contemporaneidade?

Após estudos dirigidos e oficinas (com desenhos em 3D, caricaturas, profundidades etc), promovemos exposições internas e externas a partir das técnicas do grafite, elencando os princípios identitários da comunidade local através da linguagem não verbal, expressadas em murais da escola com perguntas-chave do tipo: O que a comunidade sente, vive e expressa? Quais são as impressões sobre o entorno? Como e com quem se comunicam? O que desejam? 
Na medida em que avançávamos nos conhecimentos sobre o grafite, os debates ficavam cada vez mais ricos e calorosos. Cotidianamente informações e leituras críticas eram acrescidas aos encontros.

As técnicas experimentadas foram das mais simples (desenhos habituais) até os traços a mão feitos com pincéis em formas abstratas, rolos de espumas, máscaras de jornais ou cartolinas, desenhos vazados; além das habituais letras estilizadas.

Após experimentação destas técnicas, os grupos se organizaram para realizar o grafite nos muros da escola, em consonância com uma área temática. Ou seja, a partir dos elementos surgidos ao longo dos debates. Aproximando este elemento multicultural aos problemas socioeconômicos da realidade (juvenil) contemporânea.

A experiência com estas oficinas possibilitou dialogar com os diversos sujeitos inseridos nos processos educativos (alunos, professores, coordenadores, famílias e funcionários), revelando as potências inventivas nos/dos cotidianos escolares.

A corporeidade, portanto, potencializa os saberes e os fazeres; agencia encontros; compõe afectos; manifesta as múltiplas possibilidades de ser/estar/sentir/agir...

Assumir a corporeidade na escola é estender o corpo para o seu entorno. É entender que ela se expressa nos sentidos, nas imagens refletidas, nos silêncios falantes, nos vestígios exibidos. Enfim, em um vai-e-vem constante de práticas pedagógicas reinventadas e reencantadas (no entender de Assmann, 1998).

\section{Referências}

ARTAUD, Antonio. Eu, Antonin Artaud. Lisboa: Hiena Editora, 1988.

ASSMANN, Hugo. Paradigmas educacionais e corporeidade. Piracicaba: UNIMEP, 1995.

. Reencantar a educação: rumo à sociedade aprendente. Petrópolis: Vozes, 1998.

(C) Filosofia e Educação (Online), ISSN 1984-9605 - Revista Digital do Paideia Volume 3, Número 1, Abril de 2011 - Setembro de 2011 
. Metáforas novas para reencantar a educação: epistemologia e didática. $3^{\mathrm{a}} \mathrm{ed}$. Piracicaba: UNIMEP, 2001.

BRASIL. Parâmetros Curriculares Nacionais: $1^{\mathrm{a}}$ a $4^{\mathrm{a}}$ séries do Ensino Fundamental

- Introdução dos Parâmetros Curriculares. Brasília, DF: MEC/SEF, 1997.

CAPRA, Fritjof. A Teia da Vida. São Paulo: Cultrix, 1996.

DELEUZE, Gilles. Conversações. São Paulo, Editora 34, 1992. . O que é a Filosofia? São Paulo: Editora 34, 1992.

DELEUZE, Gilles e GUATTARI, Felix. Mil Platôs: capitalismo e esquizofrenia. São Paulo: Editora 34, 1995. . Mil Platôs: capitalismo e esquizofrenia. São Paulo: Editora 34, 1996. . Mil Platôs: capitalismo e esquizofrenia. São Paulo: Editora 34, 1997.

DELEUZE, Gilles. Diferença e Repetição. $2^{\mathrm{a}}$ ed. Rio de Janeiro: Graal, 2006.

FONTANELLA, Francisco Cock. O corpo no limiar da subjetividade. Piracicaba: Unimep,1995.

FREIRE, Paulo. A Importância do Ato de Ler: em três artigos que se completam. $22^{\mathrm{a}}$ ed. São Paulo: Cortez, 1988.

GALLO, Sílvio. Transversalidade e educação: pensando uma educação nãodisciplinar. In: ALVES, Nilda e GARCIA, Regina Leite (orgs). O Sentido da escola. $2^{\mathrm{a}}$. Ed. Rio de Janeiro: DP\&A, 2000.

. Delenze \& a Educação. Belo Horizonte: Autêntica, 2003.

Corpo Ativo e a Filosofia. In: MOREIRA, Wagner Wey (org). Século XXI: $A$ era do corpo ativo. Campinas, SP: Papirus, 2006.

MATURANA, Humberto; VARELA, Francisco. A árvore do conbecimento. Campinas, SP: Editorial Psy, 1995.

MATURANA, Humberto. Emoções e linguagem na educação e na politica. Tradução de José Fernando Campos Fortes. Belo Horizonte: Ed. UFMG, 1998.

. Cognição, ciência e vida cotidiana. Belo Horizonte: Ed. da UFMG, 2001. 
MORIN, Edgar. Articular os saberes. In: ALVES, Nilda e GARCIA, Regina Leite (orgs). O Sentido da escola. 2a ${ }^{\mathrm{a}}$. Ed. Rio de Janeiro: DP\&A, 2000.

SANT'ANNA, Denise Bernuzzi (org). Politicas do Corpo. São Paulo: Estação Liberdade, 1995.

SECRETARIA MUNICIPAL DE EDUCAÇÃO DO RIO DE JANEIRO. Núcleo Curricular Básico MultiEducação. Prefeitura da Cidade do Rio de Janeiro: 1996.

VEIGA-NETO, Alfredo. Pensar a escola como uma instituição que pelo menos garanta a manutenção das conquistas fundamentais da Modernidade. In: COSTA, Marisa Vorraber (org). A escola tem futuro? Rio de Janeiro: DP\&A, 2003. 